\title{
Figures of Style in Strangers on a Train
}

\author{
By Peter J. Dellolio
}

Fall 2006 Issue of KINEMA

\section{PARALLELISM AND PROGNOSTICATION: FIGURE OF STYLE IN STRANGERS ON A TRAIN}

"I certainly admire people who do things!"

Bruno Anthony to Guy Haines

STRANGERS on a Train is a parable about a wish fulfilment fantasy overtaking reality by means of metaphysical freedom, opposing energies, and deadly consequences. The film suggests that dangerous moral, ethical, and material forces are unleashed when conscious behaviour and subconscious wishes are in conflict. The narrative and stylistic organization of the film (based on the notion of inner-directed elements controlling the objective world) bears a general similarity to some of the precepts of Expressionism. The essential expressionist credo is that stylistic exaggerations and manipulations are commensurate with a protagonist's extraordinary anxiety and inner conflicts. For example, shortly after Miriam's (Laura Elliot) murder, there is a medium long-shot of Guy's (Farley Granger) cab pulling up to his apartment building with the bright Capitol building in the far-ground (a dissolve from Guy on the train returning to Washington precedes this long-shot). After Guy exits the cab and approaches the building, there is a medium shot as he goes up the steps followed by a closer medium shot of him opening the front door. This second shot becomes a medium close-up as Guy (hearing Bruno call his name from off-screen) turns around and moves closer to the camera, looking across the street, to the right of frame. Much later, a second pair of shots (analogous in form and function to this first pair) is used when Guy goes to the Anthony house on the pretext of agreeing to murder Bruno's (Robert Walker) father. ${ }^{(1)}$ In both sets of shots, the obliquity of the frame makes the images appear askew.

In the first example, Guy is called by Bruno and discovers Miriam is dead, a turn of events that brings its own pair of conflicting elements (relief that he's free and terror that he will be blamed). Later, the slanted framing is used to show Guy's approach to Bruno's house: first in a medium long-shot as Guy walks along the canopies, followed by a medium-shot at the doorway. Here again, the tilted framing makes the images unbalanced and tense. In both examples, Guy enters a building (his apartment, the Anthony residence). The psychological context in the first pair of shots is anticipatory anxiety: Guy is about to learn something devastating (Miriam's death) and that information controls the space. The psychological context in the second pair of shots is cumulative anxiety: Guy has reached the end of his rope in the twisted relationship with Bruno and this attempt to reason with Bruno's father is an act of desperation that controls the space. The asymmetry of the compositions is a corollary for Guy's state of mind. Interestingly, the disorientation in the first pair of shots illustrates something awry in the viewer's perception of Guy: when he goes up those steps and is called by Bruno, it is the viewer who already knows that a shocking event has occurred. It is as if the framing gesture was an expression of the viewer's anticipation of what will become an emotionally vertiginous experience for Guy. Hitchcock's contorted framing, the logical response to these psychological components, is a reformulated example of expressionist form. The oblique effect abounds in German expressionist cinema and usually signifies some kind of internal affliction for a protagonist.

Unfortunately, in both the American film noir and horror genres from the 1930s to the 1960s, this degenerated into a facile, melodramatic device when it became the conventional (inevitably clichéd) syntax for visualizing distress. In Hitchcock's hands, the slanted framing acquires a contextual justification that goes infinitely beyond thrill making, suggesting that its redundant popular use requires gross narrative motivations that oversimplify the expressive effect. Hitchcock never placed the camera in a conspicuous position unless it served a very specific psychological or narrative purpose. Consider, for example, the extreme long-shot of Roger Thornhill fleeing the United Nations building after he is blamed for Mr. Townsend's murder, taken from an aerial perspective with the camera near the roof of the building. While the canted shot may seem to be more casually woven into the stylistic fabric of Hitchcock's silent films because the influence of German 
cinematic vocabulary was obviously a more contemporaneous factor, it does not disappear after Hitchcock's arrival in Hollywood. Oblique framing does occur throughout Hitchcock's 1940's films in carefully chosen ways: Saboteur (1942), Shadow of a Doubt (1943), and Notorious (1946) contain some of the more notable examples. One must also bear in mind that the Hitchcockian style is simultaneously eclectic and unique, leading several critics to suggest that at least two films in the final period (The Birds, 1963 and Marnie, 1964) bear some similarity to the European "art" cinema of the 60 s. $^{(2)}$ Considering this, and understanding that Hitchcock was a keenly peer-conscious director, ${ }^{(3)}$ one could find some influence on these canted shots from Strangers on a Train coming from The Third Man, released two years earlier in 1949.

In examining the character of Bruno Anthony, there is a temptation to view the negative/positive transformations he injects into the world of Guy Haines as thematically reminiscent of those changes inflicted upon Gregor Samsa's family in Kafka's The Metamorphosis. If the internal premise of Guy's entire being is his wish to kill his unfaithful wife so he will be free to marry Ann Morton (Ruth Roman) and reap the rewards of a successful tennis career (not to mention the niceties of inner circle Washington politics), Bruno's obsessive dedication to the removal of Miriam Haines becomes the externalization of that premise. At the conclusion of The Metamorphosis, one may look upon Gregor's new being as a fundamental reflection of his subconscious or submerged wish to be free of the burden of providing for his family. The actualization of Gregor's wish fulfilment fantasy brings him the peacefulness of release and death; it first brings tragedy and suffering to his family but finally leaves them with self-reliance and hope. Just as the reader accepts that Gregor Samsa was a human being but is now an insect, the viewer knows that Guy Haines and Bruno Anthony are two distinct, very different people. The systems of spatial parallelism that unite them evolve from the expressionist notion that Bruno is another version of Guy: his alter ego; a doppelganger; his subconscious come to life; his suppressed will; etc. Unlike The Metamorphosis, where the split between Gregor's subconscious desires to free himself from his father's debt is in conflict with his conscious reverence for his father, in Strangers on a Train a similar conflict is divided into two "seemingly" separate characters. Bruno's resentful compliance with his father and Guy's alacritous attempts to please Senator Morton (Leo G. Carroll) strengthen this comparison with Gregor.

Gregor Samsa, having assumed total responsibility for his family's well being due in no small part to the debts incurred as a result of his father's failed business, is inexplicably transformed into a gigantic insect. That he who has for so long been regarded by his family as the sole provider should become its opposite and live out the remainder of his life as a parasite says immensely contradictory things about the internal premise of Gregor's entire being (his selfless devotion to his family's needs in direct opposition with his latent wish to be released from that responsibility). The same is also true of the members of Gregor's family: by the end of the story when Gregor dies, their long-term dependency on him has been completely reversed as they each achieve a new dignity and self-sufficiency. The connection to Guy and Bruno is derived from some of these parallels: Guy suppresses his desire to kill Miriam by subscribing to societal rules, consciously he accepts that murder is wrong; Bruno's extreme act, the killing of Miriam, can be viewed as a form of subconscious release for Guy. This act, like Gregor's transformation, is a negative event but it will ultimately make Guy purer and stronger.

Making an astute, rather off-hand comparison in his study of Orson Welles, ${ }^{(4)}$ Joseph McBride asserts that Hitchcock's The Wrong Man implements some of the elements of Kafka's The Trial. McBride alludes to the film's peculiar atmosphere of the ordinary being somehow detached from actuality; the gradual disintegration of everything that is reliable and reasonable in Manny Balestrero's (Henry Fonda) world; the austere, semidocumentary presentation of a chaotic, nightmarish situation. As McBride asserts, "Of all filmmakers, Alfred Hitchcock is the closest to Kafka."

The relationship between the premise of The Metamorphosis and that of Strangers on a Train is similar yet deeper. Gregor's implied disavowal of his responsibility for his family illuminated by his incredible transformation and Guy's latent motivation to kill Miriam objectified by Bruno's real-life incarnation of Guy's wish fulfilment fantasy share one common condition: in both examples, the fictive dream depends upon a sustained shock of belief in what is unnatural, impossible, and bizarre. It is in this arena of the fantastic depicted as natural and the ordinary depicted as bizarre that Kafka's and Hitchcock's thinking 
about the plight of modern man begin to converge. Hitchcock has a predilection for injecting the incredible, the impossible, and the fantastic into his protagonists' world while maintaining the utmost level of reality and believability within the characteristics of that depiction, resulting in what Sidney Gottlieb refers to as "the simultaneous credibility and incredibility of the Hitchcock World."(5)

Hitchcock's oeuvre is characterized by calculated spatial surprises: shocks of revelation (Notorious: the pan above the staircase culminating in the forward tracking shot to show the wine cellar key in Alicia's hand); shocks of concealment (Frenzy: the elaborate reverse tracking shot from Bob Rusk's apartment door after Babs enters); shocks of comparison (The Thirty-Nine Steps: the cleaning lady's scream blending into the train whistle); shocks of reversal (Strangers on a Train: the cut to the empty space at the other end of the Tunnel of Love when we hear Miriam's scream). These are just a few of the examples found throughout Hitchcock's work in which a moment of revelation for the viewer is delivered via some form of visual surprise or unexpected eccentricity of presentation.

This element of surprise is the crucial ingredient. Sometimes its purpose is to give dramatic emphasis to an ellipsis in the narrative flow, as in the example from The Thirty-Nine Steps; sometimes its purpose is to give the viewer a piece of privileged information, as in the example from Notorious. There are times, however, when Hitchcock varies these devices in order to register the impact upon a character of some kind of revelation or understanding that contains critical psychological significance, such as the epiphany that Roger Thornhill experiences when he learns Eve Kendall's true identity from the Professor and realizes he has inadvertently placed her life in jeopardy. The camera suddenly tracks in on Thornhill while the noise of a moving plane accompanies the illumination of light across his face, signifying, with a dash of playful irony, that Thornhill has "seen the light" and acquired a new level of insight and awareness.

The reader cannot deny that what is happening to Gregor is unbelievable while at the same time accepting the perfect verisimilitude of Kafka's prose. Albert Camus has commented on the unique contrast between the naturalism of Kafka's fiction and the dreamlike events that he often describes. ${ }^{(6)}$ Likewise, the viewer cannot deny that what is happening to Guy is the unimaginably horrifying result of an encounter with the unknown. As Ann incredulously declares when she confronts Guy outside the Morton house during the party, when he explains what has really happened with Bruno: "It's too fantastic." At the same time, the viewer must concede that Guy is better off and that in spite of his insanity Bruno is a charming man. Through the spatial entwining, synchronicity, and collation of relations between Guy and Bruno, Hitchcock generates so much ambivalence about these characters that the viewer cannot make a clear-cut judgment about them.

Yet at the conclusion of both The Metamorphosis and Strangers on a Train, there is an undeniable benefit and renewal for the surviving characters: when Bruno's dying gesture reveals Guy's lighter in his hand, the detectives realize Bruno must be the killer and Guy is free to do what he had always wanted, but now with a clear conscience. By the time Gregor dies, his mother, father, and sister have all secured good positions and look forward to the future in a new home having left Gregor's corpse and the painful memories of what he became behind. Gregor's family, like Guy, is not without blame or guilt: they had long enjoyed a comfortable lifestyle provided by Gregor without ever considering his needs. Their ordeal, like Guy's, is a test of character.

During the luncheon in Bruno's compartment, he explains his philosophy of human nature: "My theory is that everyone is a potential murderer." Complaining about his father's attempts to curtail his behaviour and force him to earn a living, Bruno admits to Guy: "I get so sore at him sometimes, I want to kill him!" (foreshadowing Guy's words when his rage over Miriam's refusal to grant the divorce makes him declare to Ann: "I could strangle her!"). The dissolve from this medium close-up of Guy in the grip of murderous anger to the close-up of Bruno's outstretched fingers after the manicure with his mother is the first connection between Guy's desires and Bruno's capacity to fulfill those desires. By the conclusion of this follow-up scene with Bruno and his parents, more personal intersections between Guy and Bruno are drawn.

Both Bruno's father and Miriam are presented at this stage of the film as antagonistic obstacles. They are depicted as hostile forces threatening to limit and control the freedom which Guy and Bruno desperately seek to enjoy, a freedom that in both cases is not altogether positive or responsible (Bruno's hedonistic indulgence in reckless pleasures: "Have you ever driven a car blindfolded at 150 miles per hour? I did"; Guy's assimilation into the Morton family circle as a way of securing a career in politics: "Marrying the 
senator's daughter has nothing to do with it! Can't a fellow look beyond a tennis net without being out for something?").

The "strangle her!" / Bruno's hands dissolve which begins this scene at the Anthony residence and the longshot of Bruno talking on the phone to Guy which concludes it economically summarize this connaturality. In the long-shot of Bruno's brief conversation with Guy when he asks if Miriam has consented to the divorce, we see Bruno's mother and father in the far-ground, arguing about his behaviour. The emphatic counterpoint within this shot, reminiscent of the deep focus photography of Citizen Kane, splits both visual and auditory concentration, as the medium close-up of Bruno in the foreground of the shot and his mostly one-sided conversation with Guy occupies our attention but at the same time we see Bruno's parents in the far-ground and hear enough of their conversation to gain further insight into Bruno's questionable behaviour: we hear Mr. Anthony speak of "hit and run driving"; of his wife having kept it from him; he speaks of sending Bruno for treatment "before it's too late," that he will have him "put under restraint" if necessary.

We hear Mrs. Anthony (Marion Lorne) being protective and defensive of her son, dismissing the "unpleasantness" always introduced by her husband. She regards and judges Bruno as though he were still a little boy. Earlier in the scene after Bruno's manicure, we see how his mother dotes on him, that she views him only as a mischievous child (she calls Bruno a "naughty boy!" after he makes her laugh when he qualifies his idea for blowing up the White House by saying: "Oh, Ma, I was only fooling! Besides, what would the President say?"). Much later, near the conclusion of the film, there is a haunting echo of Mrs. Anthony's perception of Bruno. During the carousel scene in the second fairground sequence, Guy knocks Bruno down at the beginning of their struggle. There is a low angle shot of Bruno beneath two horses after Guy's punch. Behind Guy is the child who later hits Bruno and is almost pushed off the carousel by him, who, ironically, is the same boy whose balloon was burst by Bruno in the first fairground sequence. At the moment Bruno is struck and falls to the carousel floor, the child's mother (off-screen at this point) cries out in horror: "That's my little boy!" Then a cut to the crowd shows her, repeating her cry, held back by police. This use of offscreen aural elements, employed more elaborately during Bruno's escape from Magic Isle after the murder, has a discreet power: it is Bruno who has fallen and is in danger. The cry, as yet unidentified, is laid over this shot of Bruno and resonates eerily with the helplessness of the mother who can no longer intervene on behalf of her troubled son.

At this point in the film, it appears as though there is an incontestable, decidedly one-dimensional aspect to both Mr. Anthony and Miriam. He is bullying, mean, intolerant, unreasonable, overbearing, etc. She is insincere, manipulative, conniving, shallow, repugnant, etc. A deceptive aspect of this equivalence between Guy and Bruno is that neither is at fault in any moral or ethical way. It would seem that Guy simply wants a better life in a new marriage and that Bruno is merely the harmlessly wild son of an extremely difficult rich man. It is not until after Bruno carries out his plan to "swap" murders with Guy and strangles Miriam that Mr. Anthony's excellent reasons for wanting to commit Bruno for his own good become clear and that Mrs. Anthony's inability to see her son's sickness stems from the disturbing, regressive relationship between mother and son, a psychosexual aberration that Hitchcock revisits in many of his films. Variations on these distorted mother-son relationships do occur, such as the instances of arrested development that we find in different degrees with the mother-son relationships of characters like Roger Thornhill from North by Northwest, Alex Sebastian from Notorious, or Mitch Brenner from The Birds.

Part of the film's power stems from the expressionist notion of Guy's wish fulfilment spilling uncontrollably out of a void or nether region within himself. If Guy has encountered his double or doppelganger in the figure of Bruno, a flesh and blood entity with a will and a mind of its own, then Bruno is not only an individual character but is also a metaphorical commentary on Guy's subconscious. The phrenic elements of Guy's world, his fantasy of killing Miriam, and the real elements of that world, Bruno committing this murder, will each take their toll: Miriam and Bruno both die; Guy's freedom almost costs him his life and forces him to redeem himself. The repercussions of Guy's fantasy are that he must suffer material and spiritual consequences.

When Guy joins Bruno behind the gate across the street from Guy's apartment, after the murder, Bruno answers Guy's incredulity and recriminations with: "But, Guy, you wanted it!" The certainty with which Bruno identifies Guy's true feelings about wanting Miriam out of the way amplifies the concept that Bruno's 
act is an extension of Guy's will. Just before, when Bruno gives Miriam's glasses to Guy, announcing: "I brought you a little present," there is an effect that produces ironic correlations and inferences. When Bruno hands the glasses to Guy, he is on the left of screen, his body framed so that the bars of the courtyard gate where he has been waiting enclose him in a cell-like pattern, while Guy standing opposite remains in "free" space without the gate bars.

This simply framed shot suggests several levels of meaning: Bruno has made Guy literally free of Miriam while Bruno remains free of suspicion because the motive for killing Miriam belongs to Guy, yet Bruno is artificially confined by the prison-like appearance of the gate bars. Guy's murderous wish has been realized. He is horrified not so much by the insanity of the act but by the possibility that he may be blamed, yet he enjoys the artificial freedom of his unfettered space. As William Rothman often points out, ${ }^{(7)}$ Hitchcock makes frequent use of the "bar" motif throughout his work. The emergence of this gesture, however, is not triggered in the easy, anecdotal way that Rothman indicates. Unique psychological circumstances within different narrative material, such as in the examples from Strangers on a Train discussed above, give this gesture a great deal of variety and subtlety. The device does not always convey that a character is simply and merely "imprisoned."

It is only when Guy meekly asserts, "I'm going to call the police of course!" that there is a medium-close up of his face with several bars across it. As Bruno so loyally points out, going to the police would be the same as confessing to conspiracy to commit murder. When the police car pulls up to Guy's apartment it is framed within the oval shape of the ornate wrought-iron gate, a baroque embellishment to highlight the very real fact that Guy is implicated in murder. Guy tells Bruno: "Now you've got me acting like I'm a criminal!" as he steps behind the gate to stand with Bruno in the shadows.

During the mock-strangulation of Mrs. Cunningham (Norma Varden) at the party in Senator Morton's home, Bruno reminds Mrs. Cunningham that her first impulse when especially angry at her husband is to wish him dead. When Guy makes a half-hearted assertion of "civilized" morality by saying "You can't go around killing people just because you think they're useless," Bruno's candid response reflects humanity at its worst: "What is a life or two, Guy?! Some people are better off dead!" Clearly, Bruno's character and observations serve as a commentary on the primitive and subconscious impulse potential in human nature. Certainly between Bruno and Guy there is little doubt of a dark symbiosis, but one with many paradoxical aspects. It is significant that in many ways Bruno acts with a kind of simplicity and guilelessness totally lacking in Guy whose motives are more self-serving and self-absorbed than one might first assume. A pair of examples that evokes this seemingly contradictory view of their character is the conversation between Guy and Detective Hennessey before they enter the cab and Bruno's conversation with a fairground worker while he is waiting for dusk to fall so that he can place the lighter on Magic Isle.

Since Andre Bazin coined the term "exchange of guilt"(8) to describe a narrative pattern visible throughout much of the Hitchcockian landscape, this kind of similitude between characters has become more recognizable. A few obvious examples that bear some similarity to the Guy/Bruno relationship would be pairings such as Richard Blaney / Bob Rusk from Frenzy; Father Logan / Otto Keller from I Confess; Marion Crane / Norman Bates from Psycho; L. B. Jeffries / Lars Thorwald from Rear Window; Devlin / Alex Sebastian from Notorious. The comparison with the credible yet unrealistic antiheroes such as Kafka's Gregor Samsa or Joseph K. is meant to suggest that this linkage between characters in many Hitchcock films represents more of a conceptual investment than just the transference of guilt theme that is typically observed in his work.

Like the incredible circumstances that free both Gregor and his family, it is reasonable to think of Guy and Bruno as a metaphysical equation that expresses the irresistible attraction between suppression and extroversion. In both cases, suppressed psychic material erupts and infiltrates objective reality. Gregor's transformation and Bruno's murderous act represent this psychic material in its extroverted form: Gregor puts his entire life on hold for the benefit of his family but this is not what he really wants; Guy tries to use civilized societal customs (divorce) to rid himself of Miriam but when faced with her endless subterfuge he would rather see her disposed of (murdered).

The moral irony is that Guy obviously benefits from his wife's death. His restrained desire to dispose of her violently becomes the emotional currency that fuels Bruno's maniacal behaviour. Once Guy's wishes are 
"exposed," the second phase of this exchange is that he "must" kill Bruno's father. Guy's suppressed wish to see Miriam dead is unattainable from his moral perspective but rational from a psychological perspective; Bruno's wish to kill Miriam for Guy and to have Guy eliminate his father is perfectly attainable from his moral perspective yet utterly irrational from a psychological one. The film's denouement on the runaway carousel is a visual catharsis that resolves these conflictive energies.

In all of cinema there are few single images that possess a resonance equal to the reflection of the strangulation on the lens of Miriam's fallen eyeglasses. If the film contains one supremely communicative moment that perfectly expresses the dreamlike monstrosity of Guy's wish fulfilment fantasy and Bruno's necromantic control of that fantasy, it occurs here. With the animated but distant fairground music in sardonic contrast to the silent horror of the act, the strangulation unfolds as a purely plastic occurrence, distorted and wavery like an underwater image, capturing the quintessential expressionist element of Grubelei, what Lotte H. Eisner refers to as "the eternal attraction towards all that is obscure and undetermined." (9)

Eisner goes on to assert "The Expressionists are concerned solely with images in the mind." Quoting from the theorist Kasimir Edschmid's study, Über den Expressionismus in der Literatur, she maintains that "'the chain of facts: factories, houses, illness, prostitutes, screams, hunger' does not exist; only the interior vision they provoke exists." Commenting on the 1912 expressionist play Of Der Bettler by Reinhard Sorge, she adds that the world as represented in this work "has become so 'permeable' that, at any one moment, Mind, Spirit, Vision and Ghosts seem to gush forth, exterior facts are continually being transformed into interior elements and psychic events are exteriorized. Is this not precisely the atmosphere we find in the classic films of the German cinema?" Bruno and Miriam appear gigantic in the reflection, the exaggeration mocking the traditional Hall of Mirrors carnival attraction, releasing the impetus of these expressionist notions of imagination and experience. Within the context of the eyeglass image, the "chain of facts" does not exist: we are no longer in the real world of lover's lane, Magic Isle, the fairground, Metcalf, Forest Hills, Miriam's infidelity, Guy's frustration, Bruno's insane offer.

The image has extraordinary power precisely because it does exteriorize a psychic event. A dictum illuminated by another study of Expressionism referred to by Eisner (Methode des Expressionismus by Georg Marzynski) is applied throughout every phase of Hitchcock's work: in varying degrees of density depending on the film there will always be "a selective and creative distortion [that] gives the artist a means of representing the complexity of the psyche." While the silent and sound films of the British period engage in an explorative assimilation of German film style and the American films successively refine and distil that assimilation by making the narrative motivation for visual figures more and more recondite, Hitchcock becomes the chief cinematic practitioner of expressionist thought in the middle third of the twentieth century.

That Hitchcock's films often explore the moral and emotional evolution of a character that is complacent within the ordinary only to have the extraordinary turn their world upside down is only a superficial thematic layer. Beneath this layer lies the notion of exchanged or osmotic guilt with its chaos, confusion, and potent challenges that ultimately usher the protagonist through some kind of ethical transfiguration. For example, L. B. Jefferies being almost killed by Thorwald and Devlin risking his life to rescue Alicia from Sebastian are part of the price to be paid for the moral inadequacies of these similar protagonists. Jefferies' voyeurism is used as a substitute for making an emotional commitment to Lisa; Devlin's lack of trust makes him culpable for Alicia being in a deadly situation. Guy is free of Miriam but by the end of the film he faces three desperate options: kill Bruno's father as an affirmation of his emotional implication in his wife's murder; allow himself to be arrested and charged with his wife's murder; confront Bruno and somehow prove that he is the real killer. This is an empirical surface that covers Guy's need to purify his dubious motives: using Ann as a stepping-stone to a political career in much the same way that Miriam wanted to use Guy's tennis success as a way out of her boring small-town life. When Guy enters the study before he is told the news about Miriam, he discreetly wipes away Ann's lipstick before turning around to face the Senator whom he stiffly addresses as "sir", clearly indicating a desire to show deference to him. Guy is secretly relieved that Miriam is dead and grateful that Bruno has killed her. When he raises his glass during Bruno's toast to the next Mrs. Haines in the lounge car, we can see he accepts Bruno's affirmation of his new life; when he fixes Bruno's tie after punching him at the party, he shows real concern. As Hitchcock states in the Truffaut interviews, Bruno killing Miriam is the same as Guy killing her himself. ${ }^{(10)}$ 
The runaway carousel sequence destroys the magical bond between Guy and Bruno. By rendering a nightmarish version of the carousel out of control with abnormal speed and power, Hitchcock makes an ironic comment on its role as a machine designed to induce a daydream world by slowly and playfully revolving. He demonstrates just how incredibly fast the Merry-Go-Round is spinning when the detectives who have been following Guy try to jump onto it and are instantly spun off to the ground. The couplet of low, reverse angle medium-shots of the detectives attempting their leap and then being hurled to the dirt are obliquely framed, recalling the earlier shots of Guy and indicating that a final descent into dementia and disorientation has begun. The revolutions of the carousel, gentle pleasure giver undergoing a Freudian transformation into monstrous life taker, symbolize the final, deadly circularity of the Guy/Bruno relationship.

This annularity is invoked in the last scene included in the American release but omitted from the British: the minister who recognizes Guy from the sports magazine and repeats Bruno's inquiry - "Excuse me, aren't you Guy Haines?" - demonstrating as Guy and Ann exchange telling glances and silently leave that the symmetry of tragedy can have a comic surface. The only shot given of the isolated, spinning background is from Bruno's viewpoint immediately after he jumps on. This direct link between Bruno's vision and the vertigo of the whirling space heightens the notion that Bruno has been the catalytic factor in the relationship. Guy's world has quite literally spun out of control and Bruno's role in creating this disorder has been paramount throughout the film. The twisted power of the carousel's centrifugal force metaphorically suggests that the psychic magnetism that drew Guy and Bruno together has reached an impasse and come "full circle." Consequently, all of the semantic, psychological, thematic, and philosophical parallels between Guy and Bruno are stripped away.

The horse imagery and homoerotic overtones play a role in this ritualistic violence. Bruno's ability to kill Miriam while Guy can only fantasize about it represents a form of impotence for Guy; Guy's ability to skilfully order his life while Bruno remains subservient to his father's wishes represents a form of impotence for Bruno. The homosexual pursuit, Bruno's desire for Guy's "masculine" worldliness, translates these forms of impotence into an inverted virility. Killing Miriam is itself a consummation of that virility; it as if part of what Bruno wants to impart to Guy is a substituted virility that signifies homosexual commitment, that Guy fulfilling his part and killing Mr. Anthony is Bruno's way of passing this sexual potency to Guy. The rejection for Bruno is therefore intensely sexual, as Guy's refusal to perform his murder and his confrontation with Bruno on the Merry-Go-Round demonstrate Guy's unwillingness to accept Bruno's psychosexual gift as the only way to resolve his impotence. Hence the demand for a sexually charged, ceremonial violence to serve as a backdrop for the death struggle between Bruno's savage resentment over his rejection and Guy's desperate affirmation of his volitional self.

There is the notion that, although disintegration and death are attendant conditions of his "rebirth," Gregor's transformation is a manifestation of his true self, his real self. In an expressionist context, Gregor's perception of himself assumes multiple, phantasmagoric roles: the power to create an integral world of phenomena, consequences, and renewal. It is often suggested that the bizarre ingredients of Joseph K.'s world are made illogical or demeaning because that is what K. is thinking, in spite of the distancing effect of the authorial point of view. Hitchcock's adherence to this doctrine of Expressionism, the acquisition of a metaphorical identity in opposition to the relinquishment of a literal identity, is the guiding principle of the comparison. Like Gregor's family, who by virtue of his metamorphosis assume a new individuality and become reborn as independent, strong individuals, Guy achieves what he wanted (a new beginning with Ann) only after confronting and ultimately conquering the impure and selfish impulses that originally propelled his psyche (much of the narrative in The Metamorphosis depicts the lifestyle and creature comforts provided by Gregor which his family callously take for granted). Likewise, Bruno's assumption of responsibility for a critical element in Guy's life (the disposal of Miriam) corresponds to Gregor's influence over his family's fate (as insect-parasite, Gregor forces them to become self-dependent).

Consciously or not, Hitchcock's thinking does pursue certain Kafkaesque paradigms. The implementation of Expressionism in Hitchcock's work goes far beyond the search in the 20s and 30s by the young director forging a style and digesting the immediate influence of the German film studios with which he was so closely associated. ${ }^{(11)}$ Given its demand for a pervasive, all-consuming transmogrification of sense and form, Expressionism and its depiction of the human condition seems innately connected to the illusionism of cinema. Indeed, cinematic language, its foundation based on the concept of the unreal presented as real, would appear 
to be the ideal vehicle for an expressionist imagination.

Strangers on a Train confirms that Hitchcock's Expressionism is a maturational combination of personal aesthetic choices and certain pre-established formal resources. Hitchcock the artist, the master of style, like the few truly great artists, turns this union into much more than a formula of influence by reinventing expressionist art with Hitchcockian art.

\section{Notes}

1. In his study of the director, Hitchcock's Films (New York: Paperback Library, 1970), Robin Wood suggests that outside Mr. Anthony's (Jonathan Hale) room, Guy shows hesitation as he shifts the luger from his breast pocket to his outside pocket, indicating the possibility that he may have come there to carry out "his" murder (61-62). Wood concludes that this is an intentional effect that represents a flaw in Hitchcock's realization of the scene because Farley Granger's awkward acting overemphasizes the momentary lapse of his moral integrity: according to Wood, Guy may be capable of carrying out the murder up until the moment he is surprised by Bruno in his father's bed. This is misdirected. In spite of the occasional awkwardness of Granger's performance, his behaviour and expression merely indicate that he is uncomfortable and selfconscious about the preposterous circumstances in which he finds himself: standing outside the bedroom door of a man he does not know in the middle of the night holding a gun and about to explain that the man's son is insane! The close-up of the mastiff licking Guy's hand in slow motion adds to the topsy-turvy character of the situation. It is not that Guy struggles with the temptation to carry out Bruno's wishes in order to be rid of him but that he fights an invisible battle of mixed motives within himself. Herein lies the ambivalence of Guy's character.

2. Speaking of Marnie, Joe McElhaney maintains that "While clearly emerging out of various lines of development in Hitchcock's cinema up through the 1960s, the film also seems to be trying to reach a new level of expressivity and meaning for Hitchcock. In particular, this new level relates to Hitchcock's desire to incorporate into the film certain innovations in European art cinema of the early 1960s, directly following experiments begun on The Birds a year earlier. And Marnie does, in fact, have some suggestive parallels with Antonioni's Red Desert, released the same year" J. McElhaney, "Touching the Surface" in Alfred Hitchcock: Centenary Essays, R. Allen \& S. I. Gonzales (eds.), (London: BFI Publishing, 1999) : 88.

3. Robert E. Kapsis, Hitchcock: The Making of a Reputation (Chicago \& London: The University of Chicago Press, 1992): 53. Kapsis refers to a piece by Bosley Crowther that was a follow-up to Crowther's review of Vertigo in which "[he] suggests that Hitchcock had recently become worried that Henri-Georges Clouzot, the director of the critically acclaimed Wages of Fear (1952) and Diabolique (1955), might overtake him as the international 'Master of movie suspense."'

4. Joseph McBride, Orson Welles (London: Secker \& Warburg Limited, 1972): 144.

5. Sidney Gottlieb, Hitchcock On Hitchcock (Berkeley \& Los Angeles: University of California Press, 1995): 239 .

6. Albert Camus, 'Hope and the Absurd in the Work of Franz Kafka,' from The Myth of Sisyphus (New York: Alfred A. Knopf, Inc., 1955).

7. William Rothman, Hitchcock - The Murderous Gaze (Cambridge: Harvard University Press, 1982): 139. Commenting on Hitchcock's introduction of the bar motif in a shot of Richard Hannay, the farmer John and his wife Margaret in The 39 Steps, Rothman asserts "At this charged moment, Hitchcock performs an extraordinary gesture. He cuts to a shot with the three in the background, viewed through the bars of the back of a chair, the bar motif. With this signature shot, the author steps forward and declares the imprisonment of these people."

8. Andre Bazin, 'Hitchcock vs. Hitchcock,' in Albert Lavalley (ed.), Focus On Hitchcock (Englewood Cliffs: Prentice Hall, 1972).

9. Lotte H. Eisner, The Haunted Screen: Expressionism in the German Cinema and the Influence of Max 
Reinhardt (Berkeley and Los Angeles: University of California Press, 1973): pp. 9-24.

10. Truffaut, Hitchcock, p. 199.

11. 'Early Hitchcock: the German Influence,' Sidney Gottlieb, in Hitchcock Annual, 1999-2000 (New Hampshire: Hitchcock Annual Corporation, 1999): 103. Commenting on Hitchcock's early exposure to German filmmaking, Gottlieb suggests that "we should not forget about nor underestimate the importance of shadows, stairs, mirrors, images of the double or "Doppelganger," dark foreboding landscapes, sudden terrors, and all of the other paraphernalia of many key German films of the 1920s that clearly had an effect on Hitchcock."

\section{Author Information}

Peter J. DELLOLIO has published critical essays on art and film, fiction, poetry, and drama. His poetry and fiction have appeared in various literary magazines, including Antenna, Aero-Sun Times, Bogus Review, and Pen-Dec Press. Through 1998, Peter was a contributing editor for NYArts Magazine. Currently he is working on a critical study of the films of Alfred Hitchcock. 